논 문 $16-12 S-21$

\title{
Operating Properties of Resistive Superconducting Fault Current Limiters with Various Pattern Shapes
}

\author{
Hyo-Sang Choi
}

\begin{abstract}
Quench behavior of resistive superconducting fault current limiters (SFCLs) with various pattern shapes was investigated. The pattern shapes employed were meander, bi-spiral, and spiral shapes of identical line width, gap and margin. SFCLs were fabricated from YBCO thin films grown on two-inch diameter $\mathrm{Al}_{2} \mathrm{O}_{3}$ substrates under the same conditions. The total length of current limiting paths was the shortest at the spiral shape due to its larger useless space. Inductance component of SFCLs with the spiral shape was around two times as high as those of other two shapes. This is not desirable since impedance characteristics of existing power systems can be changed. Resistance rise of current limiting elements was low at a spiral shape before the whole quench completion, which may act as a disadvantage for simultaneous quench in serial connection between current limiting elements, but the temperature tended to have similar values at higher voltages. On the other hand, bi-spiral shape was severe at insulation level between current limiting lines. When these aspects were considered, we concluded that a meander shape was appropriate to design for a resistive SFCL based on thin films except the concentration of electric field at edge areas of strip lines.
\end{abstract}

Key Words : Resistive superconducting fault current limiter, Various pattern shapes, Quench behavior, Design of a resistive SFCL

\section{INTRODUCTION}

Electrical power networks are becoming increasingly complex due to interconnection of existing power systems in order to provide higher quality and to cope with the growth of power demands. The increasing interconnection and the growing power can lead to increase fault currents over allowed currents of existing circuit breakers. These fault currents may give quite high stresses on the networks. So, it is demanded that the devices cut these short circuit currents very quickly with high reliability. Superconducting fault current limiters

조선대학교 전기공학과

(광주광역시 동구 서석동 375 ,

Fax: 062-230-7020

Corresponding Author : hyosang@chosun.ac.kr) 2003년 5월 26일 접수, 2003년 6월 27일 최종 심사완료 offer ideal performance among all current limiting devices. In normal operation the SFCL has negligible impedance since it is in the superconducting state and, in the event of a fault, the transition into the normal conducting state limits the fault current passively. SFCLs are currently being developed in many countries [1-6]. There are various concepts of SFCLs: resistive, inductive, hybrid, bridge types and so on. Resistive SFCLs are quite simple in principle and structure. Especially resistive SFCLs using thin films are easy to be made compact. We have been developing the resistive type SFCLs using thin films [6-13]. An SFCL using thin films is usually composed of several current limiting elements. In order to maximize the performance of an SFCL, the pattern shapes of the current limiting elements should be 
optimized. In this work, E-I properties by AC sources, characterization of various pattern shapes, and a proper design shape were investigated and proposed.

\section{EXPERIMENT}

Superconducting current limiting elements were fabricated using $300 \mathrm{~nm}$ thick $\mathrm{YBCO}$ thin films grown on two-inch diameter $\mathrm{Al}_{2} \mathrm{O}_{3}$ substrates. The critical current density was 2.6 $\times 10^{6} \mathrm{~A} / \mathrm{cm}^{2}$ at $77 \mathrm{~K}$ in the self field condition and uniform within $4 \%$. The critical current density was measured inductively with a coil scanning over the wafer at $77 \mathrm{~K}$ and the data were calibrated to a $1 \mu \mathrm{V} / \mathrm{cm}$ criterion. YBCO thin films generally have inhomogeneous areas that may act as hot spots when a fault current flows in the film. To disperse the Joule heat generated at hot spots, a $200 \mathrm{~nm}$ thick gold layer was coated in-situ on the YBCO thin film. Since a gold layer has much lower resistivity (about $1 / 100$ ) than that of YBCO after quench, the fault current flows in the gold layer and heat generation reduces. The gold film also protects the $\mathrm{YBCO}$ film against moisture in the air. Current limiting elements were fabricated by etching YBCO thin films into $2 \mathrm{~mm}$ wide lines by photolithography. They were patterned into various shapes such as meander, bi-spiral, and spiral. Fig. 1 shows the various patterns of the current limiting elements.

Critical current densities of edge areas were usually much lower than those of other areas. The edge areas are also likely to be damaged during experimental setup. So we used only areas within $40 \mathrm{~mm}$ diameter on wafers as current limiting elements as shown in Fig. 1. The three patterns were designed with the same values of parameters such as a diameter, width of lines, and the gap between lines to compare the properties of three samples.

Fig. 2 shows a test circuit for current limiting experiments. In this figure, $V_{0}$ is a voltage source. SFCL is a current limiting element as shown in Fig. 1 , and $R_{L}$ is the load on the line, which was $50 \Omega$. Since the SFCL should remain in the superconducting state during normal operation, it was immersed in a liquid nitrogen bath so that its temperature could be maintained at $77 \mathrm{~K}$. The circuit is under normal operation because the SFCL is in superconducting state when SW1 is closed, and under fault condition when both SW1 and SW2 are closed. Internal impedance in the source was not considered here, because its value is negligible. The values of circuit elements were determined considering critical currents and quench starting points of thin films. The data were measured using a multi-channel digitizer.

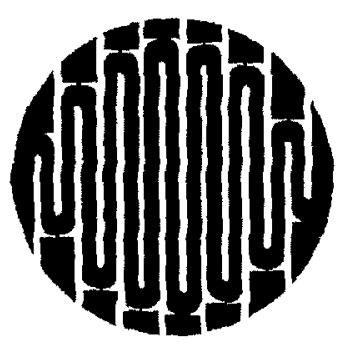

(a)

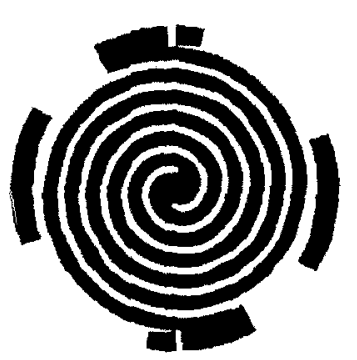

(b)

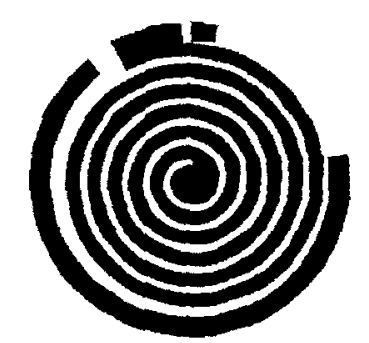

(c)

Fig. 1. The pattern shapes of current limiting elements. (a) meander shape, (b) bi-spiral shape (c) spiral shape. 


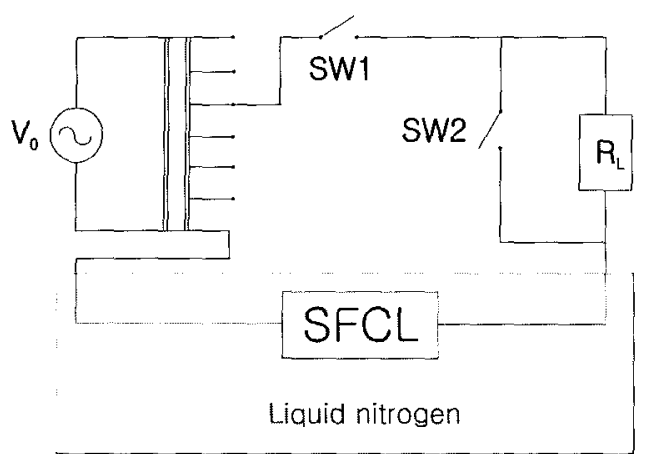

Fig. 2. Scheme of a test circuit for SFCLs.

\section{RESULTS AND DISCUSSIONS}

It is important to determine an optimal pattern shape of current limiting elements for their maximal performance. In order to compare inherent characteristics of elements with various pattern shapes, quench current densities were determined from E-I curves. In this study, three shapes of SFCL elements were used for the experiments: meander, bi-spiral, and spiral. Individual $\mathrm{E}-\mathrm{I}$ curves of these SFCL elements are shown in Fig. 3. Applied voltage of $V_{0}$ was $24 \mathrm{~V}_{\mathrm{rms}}$ here and It was applied during 3 cycles. The E-I characteristics were measured with $\mathrm{AC}$ sources because the SFCL elements will be applied in $\mathrm{AC}$ power systems.

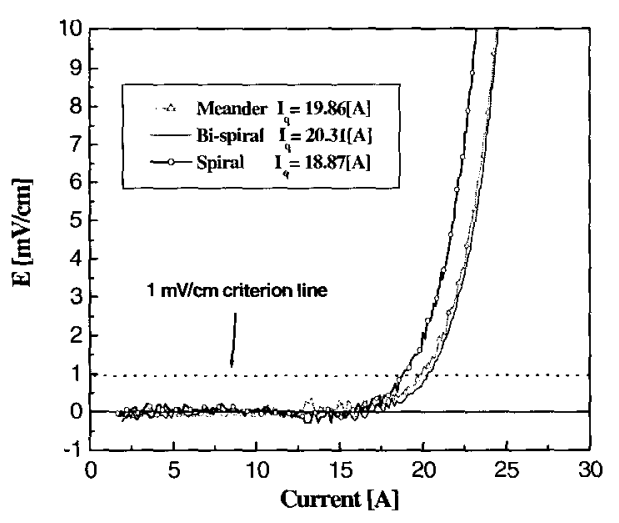

Fig. 3. E-I curves of individual SFCL elements with pattern shapes.
It can be seen from the Fig. 3 that the quench currents, $\mathbf{I}_{\mathrm{c}}$, are slightly different. The quench currents of meander shape, bi-spiral shape and spiral shape are $19.86 \mathrm{~A}, 20.31 \mathrm{~A}$ and 18.87 A, respectively. The differences were within $7 \%$. The quench current was defined to be the current at which quench started by thermal runaway. It was used to characterize SFCLs instead of the usual critical current density because it is more useful than the critical current density in practical engineering point of view. The $\mathrm{I}_{\mathrm{q}}$ line was drawn at 1 $\mathrm{mV} / \mathrm{cm}$ in Fig. 3.

Table 1 shows specific parameters of three pattern shapes at room temperature. The total resistance value of meander lines was measured to be lower than those of other shapes under the same conditions. Edge areas of meander line were designed to be slightly wider to reduce the concentration of electric field. The lower resistance of SFCL elements with meander shape is thought to have resulted from slightly lower resistance value at those areas. The length of line was the shortest at the sample of spiral shape. This means practical use is lower for spiral shape, whose voltage rating may be lower than that of other shapes of samples when other conditions including their inductance are same. In addition, the connection of current lead was also difficult at the spiral shape because one of line terminals to flow current was located in the center area of a wafer.

Table 1. Specific parameters of SFCL elements with three pattern shapes.

\begin{tabular}{|c|c|c|c|}
\hline Parameters & $\begin{array}{c}\text { Meander } \\
\text { shape }\end{array}$ & $\begin{array}{c}\text { Bi-spiral } \\
\text { shape }\end{array}$ & $\begin{array}{c}\text { Spiral } \\
\text { shape }\end{array}$ \\
\hline$* \mathrm{R}_{\mathrm{R} T}(\Omega)$ & 29.0 & 31.0 & 30.5 \\
\hline$* * \mathrm{~L}(\mathrm{~mm})$ & 378 & 377 & 354 \\
\hline
\end{tabular}

$* R_{\text {RT }}$ : Total resistance values of three pattern shapes at room temperature.

** L : Total line lengths of three pattern shapes.

Table 2 displays inductance values of three pattern shapes to estimate the effects of flux 
density. The inductance values were measured using a commercially available Agilient 4294A multi-frequency impedance analyzer, which makes it possible to measure inductance in the range of $40 \mathrm{~Hz}$ to $110 \mathrm{MHz}$ with an accuracy of $0.01 \%$. The impedance of a resistive SFCL is mostly composed of resistive component during fault operation. It can provide advantages such as waveforms without distortion, same phase between current and voltage, and no delay time at transient state, etc. The inductance value of spiral shape is about twice as high as those of two other shapes. This is due to nearly non-inductive paths of meander and bi-spiral shapes. Actually, current flows in meander and bi-spiral shapes are crossed and cancelled each other. Meander and bi-spiral shapes have an advantage at an inductance aspect.

Figure 4 shows the resistance behavior during 5 cycles after fault instant as a function of time for SFCL elements with three pattern shapes at applied voltage of $40 \mathrm{~V}_{\text {rms. }} R_{R_{T}}$ in the Fig. 4 represents the resistance of the sample measured in the room temperature, and $R(t)$ represents the resistance of the sample measured in the nitrogen bath at applied voltage of $40 \mathrm{~V}_{\mathrm{rms}}$. Resistance rise was similar right after quench instant, but the resistance after 5 cycles from quench instant was low at spiral shape. Quench was not developed completely under the applied voltage of $40 \mathrm{~V}_{\mathrm{rms}}$ since transport current was low and propagation by heat generated at quench points was slow. In addition, it is reported that the cooling efficiency near electrode areas is higher than those of other areas[9]. Therefore, we speculated that the resistance value of the spiral shape was lower because the temperature of current limiting elements increased slowly due to fast cooling by the electrode near center area. Center area of SFCLs based on YBCO films usually shows higher temperature rise [9]. This may act as a disadvantage on the point of simultaneous quench which is necessary to increase voltage rating of an SFCL through the serial connections of current limiting elements. However, this problem was solved since resistance values became almost same at higher voltages as shown in Fig. 5 .
Table 2. Inductance values of three pattern shapes.

\begin{tabular}{|c|c|c|c|}
\hline Parameters & $\begin{array}{c}\text { Meander } \\
\text { shape }\end{array}$ & $\begin{array}{c}\text { Bi-spiral } \\
\text { shape }\end{array}$ & $\begin{array}{c}\text { Spiral } \\
\text { shape }\end{array}$ \\
\hline $\begin{array}{c}\text { Superconducting } \\
\text { state inductance } \\
\text { (nH) }\end{array}$ & 557 & 552 & 943 \\
\hline $\begin{array}{c}\text { Normal state } \\
\text { inductance (nH) }\end{array}$ & 533 & 509 & 945 \\
\hline
\end{tabular}

Figure 5 represents resistance normalized to the resistance at room temperature at applied voltage of $180 V_{\text {rms. }}$. The temperature of each samples increased up to $238 \mathrm{~K}$ after 5 cycles from quench instant and resistance rise behavior was almost the same. It was proved by our experiments that current limiting elements could be operated safely against degradation and aging up to $250 \mathrm{~K}$ [6]. So, we did not increase the applied voltage any further. We found that the temperature rise behavior was similar, since quench was completed at this voltage and since generated heat was mainly propagated through the substrate afterwards [4]. In other words, the quench characteristics of three pattern shapes were similar at maximum applied voltage.

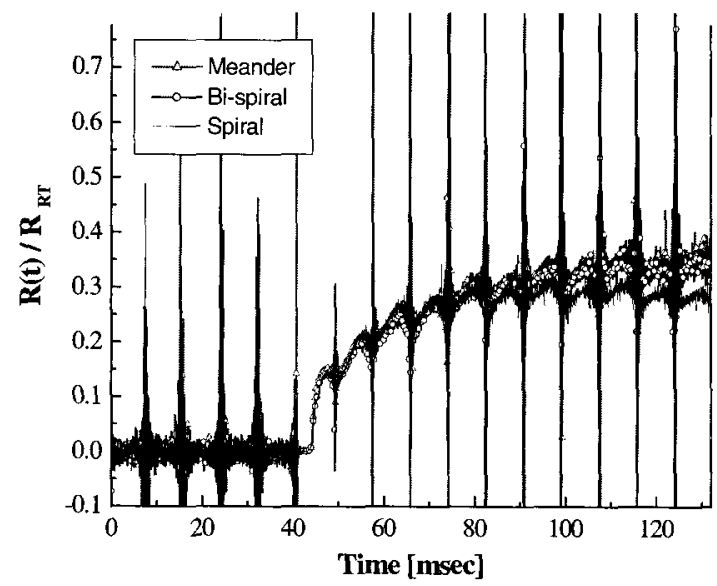

Fig. 4. The resistance normalized to the room temperature resistance of three pattern shapes as a function of time (applied voltage : $40 \mathrm{~V}_{\text {rms }}$, fault angle : 0 ). 


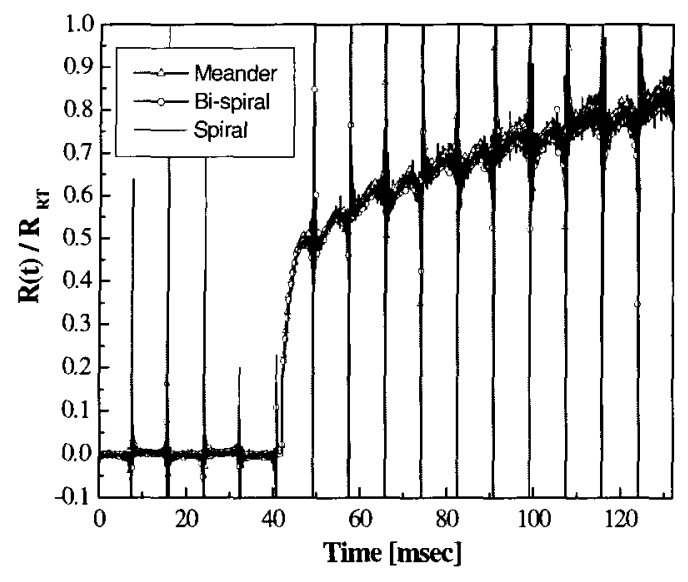

Fig. 5. The resistance normalized to the room temperature resistance of three pattern shapes as a function of time (applied voltage : $180 \mathrm{~V}_{\text {rms }}$, fault angle : 0 ).

Table 3. Maximum voltage between near current limiting lines of three pattern shapes at applied voltage of $180 \mathrm{~V}$ rms.

\begin{tabular}{|c|c|c|c|}
\hline Parameters & $\begin{array}{c}\text { Meander } \\
\text { shape }\end{array}$ & $\begin{array}{c}\text { Bi-spiral } \\
\text { shape }\end{array}$ & $\begin{array}{c}\text { Spiral } \\
\text { shape }\end{array}$ \\
\hline $\begin{array}{c}\mathrm{E}_{\text {peak }} \\
(\mathrm{V} / \mathrm{cm})\end{array}$ & 5.89 & 5.97 & 6.35 \\
\hline $\mathrm{L}_{\max }(\mathrm{cm})$ & 7.63 & 26.54 & 10.93 \\
\hline $\mathrm{V}_{\max }(\mathrm{V})$ & 44.9 & 158.4 & 69.4 \\
\hline
\end{tabular}

Finally, we investigated the insulation properties of current limiting lines and showed the results in table 3 . In order to determine maximum voltages between the nearest lines, we calculated electric field in SFCLs with three pattern shapes at applied voltage of $180 \mathrm{~V}_{\mathrm{rm} \text { s. }}$, chose the longest section between the nearest lines, and then obtained the maximum voltage by multiplying the peak electric field $E_{\text {peak }}$ and $L_{\text {max. }}$ An SFCL with bi-spiral shape had the highest maximum voltage of $158.4 \mathrm{~V}_{\text {peak, while }}$ an SFCL with meander shape had the maximum voltage of only $44.9 \quad \mathrm{~V}_{\text {peak. }}$ We have not investigated yet how samples will endure without breakdown of insulation within the gap of $1 \mathrm{~mm}$ between current limiting lines. However, if the applied voltage is increased, bi-spiral shape may have more severe insulation problems than those of other shapes. This makes it possible to lower the insulation level at the same applied voltage in case of SFCLs with the meander shape.

\section{CONCLUSION}

Three pattern shapes have been designed, constructed, and tested to determine optimal shape of current limiting elements for their power applications. They are meander, bi-spiral and spiral shapes. They were designed with the same values of parameters such as diameter, width of lines, and the gap between lines to compare the properties of three samples. YBCO thin films with two-inch diameter were used for construction of these shapes. The length of line at the spiral shapes was shorter up to about 7 $\%$ than other shapes, which means its voltage rating may be lower than other shapes. The inductance components were the highest at spiral shape due to nearly non-inductive structures of meander and bi-spiral shapes. Insertion of inductance components is not desirable since impedance characteristics of existing power systems are slightly changed. So, meander and bi-spiral shapes have an advantage at an inductance aspect. Resistance rise behavior of these pattern shapes at maximum applied voltage was almost same. That is, quench behavior of three pattern shapes was similar. Finally, we investigated maximum voltage drop between current limiting lines at applied voltage of $180 \mathrm{~V}_{\text {rms. }}$. The highest voltage occurred at bi-spiral shape as $158.4 V_{\text {rms }}$ while voltage of $44.9 \mathrm{~V}_{\mathrm{rms}}$ occurred at meander shape. This makes it possible to lower the insulation level at the same applied voltage in case of SFCLs with the meander shape. We concluded the meander shape was appropriate as a pattern shape to design a resistive SFCL using YBCO films except the concentration of electric field. 
However, further research is still needed to design optimal shape in terms of electromagnetic behavior, local heating properties, and $\mathrm{AC}$ loss, etc.

\section{REFERENCES}

[1] T. Hoshino, K. M. Salim, M. Nishikawa, I. Muta, and T. Nakamura, "DC reactor effect on bridge type superconducting fault current limiter during load increasing", IEEE Trans. on Appl. Supercon., Vol. 11, No. 1, p. 1944, 2001.

[2] H. Shimizu, K. Kato, Y. Yokomizu, T. Matsumura, and N. Murayama, "Resistance rise in Bi2223 superconducting bulk after normal transition due to overcurrent", IEEE Trans. on Appl. Supercon., Vol. 11, No, 1, p. $1948,2001$.

[3] M. Noe, K. P. Juengst, F. Werfel, L. Cowey, A. Wolf, and S. Elschner, "Investigation of high-Tc bulk material for its use in resistive superconducting fault current limiters", IEEE Trans. on Appl. Supercon., Vol. 11, No. 1, p. 1960, 2001.

[4] A. Heinrich, R. Semerad, H. Kinder, H Mosebach, and M. Lindmayer, "Fault current limiting properties of YBCO-films on sapphire substrates", IEEE Trans. on Appl. Supercon., Vol. 9, No. 2, p. 660, 1999.

[5] K. Tekletsadik and M. Saravolac, "Development of a 7.5 MVA superconducting fault current limiter", IEEE Trans. on Appl. Supercon., Vol. 9, No. 2, p. 672, 1999.

[6] H. S. Choi, H. R. Kim, O. B. Hyun, and S. J. Kim, "Quench properties of $\mathrm{Y}-\mathrm{Ba}-\mathrm{Cu}-\mathrm{O}$ films after overpowering quenches", IEEE Trans. on Appl. Supercon., Vol. 11, No. 1, p. $2418,2001$.

[7] H. R. Kim, H. S. Choi, H. R. Lim, I. S Kim, and O. B. Hyun, "Initial quench development in uniform $\mathrm{Au} / \mathrm{Y}-\mathrm{Ba}-\mathrm{Cu}-\mathrm{O}$ thin films", IEEE Trans. on Appl. Supercon., Vol. 9, No. 2, p. 2414, 2001.
[8] H. S. Choi, H. R. Kim, and O. B. Hyun, "Operating properties of superconducting fault current limiters based on YBCO thin films", Cryogenics, 2001. Vol. 41, No. 3, p. $163,2001$.

[9] H. R. Kim, H. S. Choi, H. R. Lim, I. S. Kim, and O. B. Hyun, "Quench distribution in superconducting fault current limiters at various voltages", Cryogenics, 2001. Vol. 41, No. 4, p. 275, 2001.

[10] H. S. Choi, O. B. Hyun, and H. R. Kim, "Quench characteristics of resistive superconducting fault current limiters based on YBCO films", Physica C, Vol. 351, No. 4, p. $415,2001$.

[11] H. S. Choi, O. B. Hyun, H. R. Kim, and S. D. Hwang, "Characteristics of $15 \mathrm{kVA}$ superconducting fault current limiters using thin films", J. of KIEEME(in Korean), Vol. 13, No. 12, p. $1058,2000$.

[12] H. R. Kim, O. B. Hyun, H. S. Choi, S. D. Hwang, and S. J. Kim, "Quench propagation in resistive SFCL", J. of KIEEME(in Korean), Vol. 13, No. 4, p. 337, 2000.

[13] H. S. Choi, S. D. Hwang, and O. B. Hyun, "Current limiting characteristics of a resistive SFCL for a single-line- to- grounf fault in the $22.9 \mathrm{kV}$ system", J. of KIEEME(in Korean), Vol. 14, No. 6, p. 505, 2001. 